\title{
Measuring Neighborhood Order and Disorder: a Rapid Literature Review
}

\author{
Steeve Ndjila ${ }^{1} \cdot$ Gina S. Lovasi ${ }^{1} \cdot$ Dustin Fry ${ }^{1} \cdot$ Amélia A. Friche $^{2}$ \\ Published online: 26 November 2019 \\ (C) The Author(s) 2019
}

\begin{abstract}
Purpose of Review Neighborhood disorder has received attention as a determinant of health in urban contexts, through pathways that include psychosocial stress, perceived safety, and physical activity. This review provides a summary of data collection methods, descriptive terms, and specific items employed to assess neighborhood disorder/order.

Recent Findings The proliferation of methods and terminology employed in measuring neighborhood disorder (or neighborhood order) noted over the past two decades has made related studies increasingly difficult to compare. Following a search of peerreviewed articles published from January 1998 to May 2018, this rapid literature review identified 18 studies that described neighborhood environments, yielding 23 broad terms related to neighborhood disorder/order, and a total of 74 distinct measurable items.

Summary A majority of neighborhood disorder/order measurements were assessed using primary data collection, often relying on resident self-report or investigatory observations conducted in person or using stored images for virtual audits. Items were balanced across signs of order or disorder, and further classification was proposed based on whether items were physically observable and relatively stable over time.
\end{abstract}

Keywords Neighborhood disorder $\cdot$ Neighborhood environments $\cdot$ Street observations $\cdot$ Virtual audits $\cdot$ Physical disorder

\section{Introduction}

Neighborhood conditions are increasingly recognized as having an important impact on the health of neighborhood residents beyond what can be explained by individual-level characteristics alone [1]. Neighborhood characteristics have therefore gained attention in health-related research for several psychosocial and behavioral pathways over the past two decades [2-5]. Adding to this momentum, Exposure Science in the $21^{\text {st }}$ Century: A Vision and a Strategy report released in 2012 by

This article is part of the Topical Collection on Built Environment and Health

Gina S. Lovasi gs145@drexel.edu

1 Urban Health Collaborative, Dornsife School of Public Health, Drexel University, 3600 Market St, 7th Floor, Philadelphia, PA 19104, USA

2 Belo Horizonte Observatory for Urban Health, School of Medicine, Federal University of Minas Gerais, Belo Horizonte, Brazil the National Research Council (NRC) pointed out a need for more comprehensive exposure data collection procedures that include environmental and community characteristics in addition to individual-level exposures [6].

As the body of literature on neighborhood characteristics has grown, so has the list of terms used to describe these characteristics, and several distinct classification schemes have been proposed $[2-5,7,8,9 \bullet, 10-12]$. Given this proliferation and diversification of neighborhood-assessment tools and terminology, distinctions and relationships between concepts can be complex to navigate, making related research challenging to identify and interpret. Consolidation and clear delineation of concepts are made even more important by the emergence of multinational collaborations such as the Salud Urbana en América Latina (Urban Health in Latin America, SALURBAL) project [13••] which includes spatial and temporal comparisons relevant to understanding how urban environments affect population health [14•, 15•]. Quistberg, Roux $\left[16 \bullet^{\bullet}\right]$ further emphasizes the necessity for ensuring comparability of measures across various secondary data from distinct urban settings (cities and sub-cities). However, secondary data are not uniformly available for all aspects of health-relevant 
urban environmental variation, particularly for indirectly measured concepts such as neighborhood disorder.

Neighborhood disorder/order has emerged as a particularly prominent term that is cited in a large collection of healthrelated research $[3,7,9 \bullet, 10,17]$. For example, Latkin, Curry [3] report direct associations between neighborhood disorder indicators such as vandalism, littering and/or loitering, and high-risk substance use and sexual behavior patterns. Although the concept of neighborhood disorder is used extensively, it is not always defined explicitly. Available literature shows a gradual evolution of the framing of physical disorder as a potential signal of social context and determinant of health. One of the earliest views of the term neighborhood disorder defines it as a pattern of divergence away from conventionally accepted norms or standards within a community [18]. This may be manifested as the perceptible decay of the urban scenery or the proliferation of uncivil social behavior and resultant physical signs such as broken windows or an accumulation of litter [19-21]. Ross and Jang [22] built on this early view and introduced a second perspective that highlights the presence of measurable neighborhood processes or items such as vandalized or abandoned property (including both vacant lots, buildings, and vehicles) as indicators of neighborhood disorder. This work brought to prominence the idea that neighborhood disorder is not always criminal in nature but is inclusive of a range of criminalized and noncriminal factors that indicate substandard neighborhood maintenance or affinity such as graffiti, buildings in states of disrepair, and loitering. Today, a third and more prominent view of neighborhood disorder focuses more on perception of the neighborhood by residents as a stressor, incorporating a more subjective lens. Under this definition, neighborhood disorder is described as a generally perceived lack of order and social control within a community [23]. Neighborhood residents and/or investigators see visible cues and decide whether to interpret them as indicators of neighborhood disorder based on their preconceptions. This allows for awareness of how subjectivity can influence ratings, as the same neighborhood feature could be viewed as indicating disorder by one viewer but not by another. Even when residents or researchers would agree that an item indicates disorder, there may be disagreement about the degree to which disorder is perceived (slight to severe). For pathways involving resident stress-related or behavioral responses to the environment, attention to how residents (vs researchers) perceive the environment may be particularly crucial.

In this review, we aim to provide an orientation to some common terms used in describing neighborhoods, including broader terms related to the disorder/order spectrum and the specific items measured to characterize these terms. This will help contextualize current findings and guide the description and consolidation of measurement strategies which to date have been highly variable.

\section{Study Design}

A rapid review of the literature on neighborhood disorder and health was conducted to identify common terminology and to provide guidance on measurement options relevant to future data collection for neighborhood-scale investigations globally.

\section{Identification and Inclusion of Papers}

To begin the search, the terms "neighborhood disorder" and "physical disorder" were in turn entered in a search box that was restricted to article titles only on the National Center for Biotechnology Information (NCBI) web database, PubMed. Peer-reviewed English language articles published from the year 1998 through May 2018 (20 years span) were then selected through a snowball approach [24] starting with a recently published original research article by Robinette, Charles [25••] published in Social Science and Medicine in 2018. Informed by this search, cited articles with similar and related terms were also identified.

Inclusion criteria were (1) assessment of neighborhood disorder/order and related terms using measurable items (or descriptions) via primary data (in-person, virtual, and/or selfreport) and/or secondary data sources and (2) complete information about assessed neighborhood characteristics (reporting all street level items used to assess each neighborhood characteristic) (Fig. 1).

\section{Characterization of Data Collection Methods and Included Items}

Information abstracted from included articles allowed categorization of data collection methods and identification of unique terms and items (Table 1). We distinguished methods to characterize the neighborhood environment as primary (collected by the investigators for research purposes) or secondary data (available from prior research or surveillance efforts, commonly including publicly available data). Studies that used primary data were further categorized with attention to the groupings relevant to whether residents or investigators were engaged in measurement and whether any systematic observation was in-person or virtual. In-person data collection included only studies that trained people to conduct data collection via systematic in-person observations in the neighborhoods of interest. Examples include Kelly, Schootman [11], Wei, Hipwell [26], and Douglas, Briones [9•]. Another such study beyond the scope of our search (screened out prior to full inclusion criteria assessment due to our restriction to English language publications) is Costa, Mingoti [27]. Virtual audit data collection included studies that made use of stored imagery such as Google Street View images. Examples include Marco, Gracia [12], Mooney, Bader [28], and Sampson and Raudenbush [21]. Self-report included 


\section{Primary Online Search}

PubMed (Search Words: Neighborhood

Disorder, Physical disorder)

73 Papers: 55 for Neighborhood Disorder and 18 for Physical Disorder

Title \& Abstract Screening

Robinette, Charles (25••) selected for secondary search initiation

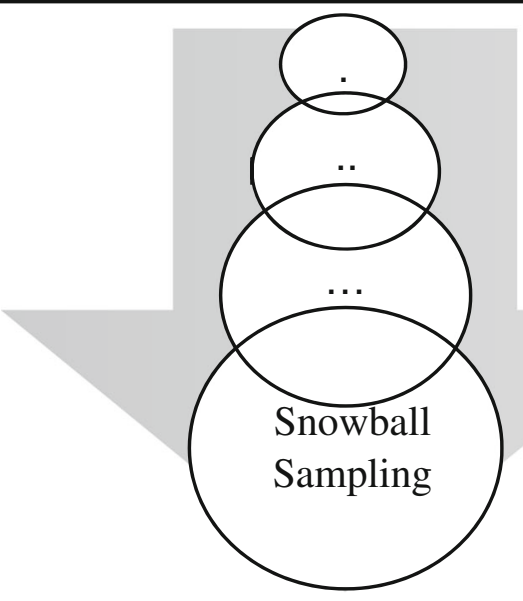

25 papers ready for full text review

Excluded (7 Papers)
Papers did not meet
inclusion criteria

Full text review of papers using inclusion criteria.

1. Assessment of neighborhood disorder/order or related terms using observable items

2. Provide information about each item measured

\section{8 papers selected for final review}

Fig. 1 Identification and inclusion of papers in this rapid review

surveys or interviews with residents reflecting on the characteristics of their neighborhood, an area for which the boundaries were often not explicitly specified. An example of a study that used this data collection procedure is Oropesa [29]. Other similar studies beyond the scope of our search (due to our restriction to English language publications) 
include de Almeida Célio, de Lima Friche [30] and Andrade, Peixoto [31].

For each article included in this review, all reported items used in measuring neighborhood characteristics were extracted and initially categorized using terms drawn from the articles themselves. The same specific item could be grouped under multiple broader terms by different articles. Some very similar items were different only based on measuring presence vs absence, and thus could be considered as the inverse (or reverse coding) of each other. For example, Zandieh, Martinez [32] measured litter, placing emphasis on the absence of litter to signal neighborhood order, while Kelly, Schootman [11] also measured litter but focused on presence of litter to indicate neighborhood disorder. To simplify our representation of the items, descriptive terms such as good, bad, high level of, or presence/absence were omitted to distill a shorter list of measurable items. Hence, for both studies named above, the item extracted was "litter/trash/rubbish." Articles from which the items were drawn were also noted such that each item was associated with an original source reference.

Following this initial extraction of items, the team of authors developed through consensus a stratification system based on three ways to divide the items: (1) order/disorder, whereby each item was determined as indicating either order or disorder; (2) physical/social, whereby each item was assessed for whether it would be apparent through observing the physical environment or through social dynamics; and (3) temporary/stable, whereby each item was assessed for likely short-term variation (hours, days, or weeks) or relative stability (though still subject to longer-term transitions, stable items were thought to be less sensitive to the exact timing of observation). This scheme to stratify items was devised with attention to both capturing a range of positive and negative aspects of urban areas, as well as to show how the nature of items might restrict our options for measurement. For example, physical factors such as litter and graffiti may be more suitable to systematic observation, whereas social dynamics such as trust in neighbors and community unity may not be as readily observable by investigators using virtual or even in-person audits. Although all aspects of neighborhood disorder in general have social causes and psychosocial consequences, not all are detectible from the visible features of the environment. Finally, our classification of items as relatively temporary versus stable is relevant to reliability in capturing a state of the environment such as noise or litter which can vary throughout the day or week. Further refinement to our assessment of which items are stable may be particularly well captured through carefully timed, repeated in-person audits. Where short-term fluctuations are relatively large, the timing of virtual audits that rely on available imagery may be an important limitation. Likewise, self-reported neighborhood characteristics that generally rely on observations over an unspecified

Table 1 Characteristics of articles reviewed

\begin{tabular}{|c|c|c|c|}
\hline Study & Type of data collected & $\begin{array}{l}\text { Primary data collection } \\
\text { protocol }\end{array}$ & $\begin{array}{l}\text { Party assessing } \\
\text { disorder/order }\end{array}$ \\
\hline Bowling, Barber, Morris, and Ebrahim (2006) & Primary data & Self-report (interviews) & Participants \\
\hline Cunradi (2009) & Primary data & Self-report (interviews) & Participants \\
\hline Latkin, Curry, Hua, and Davey (2007) & Primary data & Self-report (interviews) & Participants \\
\hline Latkin et al. (2017) & Primary data & Self-report (interviews) & Participants \\
\hline Litt et al. (2011) & Primary data & Self-report (interviews) & Participants \\
\hline Miles (2008) & Primary data & $\begin{array}{l}\text { Self-report (interviews) } \\
\text { and in-person }\end{array}$ & $\begin{array}{c}\text { Participants and } \\
\text { investigators }\end{array}$ \\
\hline Oropesa (2012) & Primary data & Self-report (interviews) & Participants \\
\hline Robinette, Charles, and Gruenewald (2018) & Primary data & Self-report (interviews) & Participants \\
\hline Ross and Mirowsky (2001) & Both primary and secondary data & Self-report (interviews) & Participants \\
\hline Zandieh, Martinez, Flacke, Jones, and Van Maarseveen (2016) & Primary data & Self-report (interviews) & Participants \\
\hline Douglas et al. (2018) & Primary data & In-person & Investigators \\
\hline Kelly, Schootman, Baker, Barnidge, and Lemes (2007) & Primary data & In-person & Investigators \\
\hline Wei, Hipwell, Pardini, Beyers, and Loeber (2005) & Both primary and secondary data & In-person & Investigators \\
\hline Marco, Gracia, Martín-Fernández, and López-Quílez (2017) & Primary data & Virtual & Investigators \\
\hline Mooney et al. (2014) & Primary data: & Virtual & Investigators \\
\hline Sampson and Raudenbush (1999) & Primary data & Virtual & Investigators \\
\hline Cerdá et al. (2009) & Secondary data & $\mathrm{N} / \mathrm{A}$ & $\mathrm{N} / \mathrm{A}$ \\
\hline Mason et al. (2017) & Secondary data & N/A & N/A \\
\hline
\end{tabular}

Primary data refers to data collected by the investigators for research purposes

Secondary data refers to data available from prior research or surveillance efforts, commonly including publicly available data 
Table 2 List of street-level items categorized by terms

Term $\quad \begin{aligned} & \text { Number of } \\ & \text { studies using } \\ & \text { this term }\end{aligned}$

Physical disorder/order $[8,11$, $12,21,25 \bullet \bullet, 26,28,33,34]$

Social disorder/order

$[21,25 \bullet \cdot, 29,33]$

Neighborhood disorder/ order [5, 9, 17, 35]
Abandoned vehicles

Auditory annoyance (noise)

Bar-windowed buildings

Broken glass/windows

Cigarette butts

Cleanliness

Deteriorated buildings

Empty bottles (beer or liquor)

Graffiti (with or without political message or protest) and graffiti painted over

House maintenance

Litter/ trash/ rubbish

Needles/ syringes

Sex Paraphernalia

Vacant/abandoned buildings (homes and others)

Vacant/abandoned buildings (homes and others)

Vacant/abandoned or undeveloped land

Vandalism

Vandalized or run-down buildings

Vegetation (artificial and man-made)

Cleanliness

Crime (assaults, robbery, muggings...)

Drug use and/or trafficking

Gangs

Respect for rules, laws, and authority

Perceived nighttime street safety

Loitering

Alcohol use

Street fights (and disputes)

Prostitution

interpersonal relationships

Willingness to help neighbors

Perceived neighborhood safety

Alcohol use

Auditory annoyance (noise)

Broken glass/windows

Crime (assaults, robbery, muggings...)

Dog refuse

Drug use and/or trafficking

Graffiti (with or without political message

or protest) and graffiti painted over

Litter/ trash/ rubbish

Loitering

Owner-occupied housing

Poverty (household and individual)

Sex Paraphernalia

Single-parent households

Street fights (and disputes) 
Table 2 (continued)

\begin{tabular}{lll}
\hline Term & $\begin{array}{l}\text { Number of } \\
\text { studies using } \\
\text { this term }\end{array}$ & Street-level item measured \\
\hline
\end{tabular}

Vacant/abandoned buildings (homes and others)

Neighborhood safety [29, 32]

Neighborhood aesthetics [4, 32]

Neighborhood air quality [32]

Neighborhood amenities [32]

Neighborhood attachment [4]

Neighborhood characteristics [26]

Neighborhood cohesion [25••]

Neighborhood disadvantage [33]

Neighborhood Interaction (social cohesiveness or neighborhood cohesiveness) [29]

Neighborhood political engagement [2]

Neighborhood problems [2]

Neighborhood quietness [32]

Neighborhood sidewalks [11]

Neighborhood social involvement [4]
Vandalism

Vegetation (artificial and man-made)

Attractive sites (natural and man-made)

Litter/ trash/ rubbish

Shade

Vegetation (artificial and man-made)

Well-maintained front gardens

Crime (assaults, robbery, muggings...)

Pedestrian interaction

Pedestrian visibility

Perceived daytime street safety

Perceived nighttime street safety

Street lighting

Exhaust fumes

Public benches

Public toilets

Shelters

Emotional attachment to neighborhood facilities Sense of belonging to neighborhood

Minority concentration

Poverty (household and individual)

Vacant/abandoned buildings (homes and others)

Interpersonal solidarity

Sense of belonging to neighborhood

Adults 25+ with college degrees

Mother-only households

Owner-occupied housing

Poverty (household and individual)

Community unity

Interpersonal professional discussions

interpersonal relationships

Interpersonal social visits

Trust in neighbors

Willingness to help neighbors

Participation in elections

Air quality

Auditory annoyance (noise)

Crime (assaults, robbery, muggings...)

Graffiti (with or without political message or protest) and graffiti painted over

Litter/ trash/ rubbish

Speed/volume of traffic (including nearby streets) Auditory annoyance (noise)

Sidewalk walkability

Sidewalks

Advocacy for neighborhood issues 
Table 2 (continued)

\begin{tabular}{|c|c|c|}
\hline Term & $\begin{array}{l}\text { Number of } \\
\text { studies using } \\
\text { this term }\end{array}$ & Street-level item measured \\
\hline & & $\begin{array}{l}\text { Participation in local activities } \\
\text { Participation in neighborhood meetings }\end{array}$ \\
\hline $\begin{array}{l}\text { Neighborhood traffic } \\
\text { condition [32] }\end{array}$ & 1 & $\begin{array}{l}\text { Crosswalks and pedestrian signaling } \\
\text { Perceived safety of crosswalks } \\
\text { Respect of driving rules } \\
\text { Speed/volume of traffic (including nearby streets) }\end{array}$ \\
\hline Neighborliness [2] & 1 & $\begin{array}{l}\text { interpersonal relationships } \\
\text { Perceived nighttime street safety } \\
\text { Trust in neighbors }\end{array}$ \\
\hline $\begin{array}{l}\text { Perceived neighborhood } \\
\text { disorder/order [3] }\end{array}$ & 1 & $\begin{array}{l}\text { Crime (assaults, robbery, muggings...) } \\
\text { Drug use and/or trafficking } \\
\text { Litter/ trash/ rubbish } \\
\text { Loitering } \\
\text { Vacant/abandoned buildings (homes and others) } \\
\text { Vandalism }\end{array}$ \\
\hline $\begin{array}{l}\text { Perceived neighborhood } \\
\text { environment [2] }\end{array}$ & 1 & $\begin{array}{l}\text { Attractive sites (natural and man-made) } \\
\text { Commercial facilities (shops) } \\
\text { Facilities for people aged } 65+ \\
\text { Leisure/social facilities } \\
\text { Local health services } \\
\text { Rubbish collection } \\
\text { Transport }\end{array}$ \\
\hline $\begin{array}{l}\text { Perceived neighborhood } \\
\quad \text { safety [34] }\end{array}$ & 1 & Perceived nighttime street safety \\
\hline Physical decay [12] & 1 & $\begin{array}{l}\text { Deteriorated recreation places } \\
\text { Deteriorated residential units } \\
\text { Vacant/abandoned buildings (homes and others) } \\
\text { Vandalized or run-down buildings }\end{array}$ \\
\hline
\end{tabular}

period may mask important variation over time. Stable items such as deteriorated buildings may be more reliably observable across a range of data collection techniques, while still being amenable to deliberate community investment efforts such as urban redevelopment (Table 1).

\section{Current Findings}

The initial title search yielded 73 results in total: 55 for the term "neighborhood disorder" and 18 for the term "physical disorder." After screening titles to determine which papers assessed neighborhood disorder/order and using a snowball sampling methodology, 25 papers were selected for review. After full text review of these selected papers, 18 met our inclusion criteria.

The review yielded 23 distinct terms (including neighborhood disorder/order themselves) used to describe neighborhood environments with a total of 74 specific items measured to assess them (Table 2).

Stratifying the 74 items (disorder/order, physical/social, or temporary/stable) yielded the following results: 43 items described order and related concepts, while the remaining 31 items described disorder and related concepts; 36 items fell under the category physical, while the remaining 38 items fell under the category social; 31 items fell under the category temporary, while the remaining 43 items fell under the category stable (Table 3 ). We note that there may be efforts needed to avoid conflation of neighborhood social disorder with commonly measured social determinants of health based on population characteristics.

\section{Discussion}

During the categorization of the 23 neighborhood disorder/ order related terms identified (such as neighborhood 
Table 3 List of street-level items categorized by descriptive category

\begin{tabular}{|c|c|c|c|}
\hline & & Physical & Social \\
\hline \multirow[t]{2}{*}{$\begin{array}{l}\text { Order (absence of these items } \\
\text { indicates disorders) }\end{array}$} & Temporary & $\begin{array}{l}\text { - Cleanliness } \\
\text { - Shade } \\
\text { - Shelters } \\
\text { - Sidewalk walkability } \\
\text { - Vegetation (artificial and man-made) } \\
\text { - Well-maintained front gardens }\end{array}$ & $\begin{array}{l}\text { - Community unity } \\
\text { - Interpersonal professional discussions } \\
\text { - Interpersonal social visits } \\
\text { - Participation in neighborhood meetings } \\
\text { - Pedestrian interaction } \\
\text { - Pedestrian visibility } \\
\text { - Perceived daytime street safety } \\
\text { - Perceived nighttime street safety } \\
\text { - Respect of driving rules } \\
\text { - Willingness to help neighbors }\end{array}$ \\
\hline & Stable & $\begin{array}{l}\text { - Air quality } \\
\text { - Attractive sites (natural and Man-made) } \\
\text { - Commercial facilities (shops) } \\
\text { - Crosswalks and pedestrian signaling } \\
\text { - House maintenance } \\
\text { - Leisure/social facilities } \\
\text { - Local health services } \\
\text { - Owner-occupied housing } \\
\text { - Public benches } \\
\text { - Public toilets } \\
\text { - Sidewalks } \\
\text { - Street lighting } \\
\text { - Transport }\end{array}$ & $\begin{array}{l}\text { - Adults } 25+\text { with college degrees } \\
\text { - Advocacy for neighborhood issues } \\
\text { - Emotional attachment to neighborhood facilities } \\
\text { - Facilities for people aged } 65+ \\
\text { - interpersonal relationships } \\
\text { - Interpersonal solidarity } \\
\text { - Participation in elections } \\
\text { - Participation in local activities } \\
\text { - Perceived neighborhood safety } \\
\text { - Perceived safety of crosswalks } \\
\text { - Respect for rules, laws, and authority } \\
\text { - Rubbish collection } \\
\text { - Sense of belonging to neighborhood } \\
\text { - Trust in neighbors }\end{array}$ \\
\hline \multirow[t]{2}{*}{$\begin{array}{l}\text { Disorder (presence of these } \\
\text { items indicates disorder) }\end{array}$} & Temporary & $\begin{array}{l}\text { - Abandoned vehicles } \\
\text { - Broken glass/windows } \\
\text { - Cigarette butts } \\
\text { - Dog refuse } \\
\text { - Empty bottles (beer or liquor) } \\
\text { - Litter/trash/ rubbish } \\
\text { - Needles/ syringes } \\
\text { - Sex Paraphernalia }\end{array}$ & $\begin{array}{l}\text { - Alcohol use } \\
\text { - Auditory annoyance (noise) } \\
\text { - Drug use and/or trafficking } \\
\text { - Gangs } \\
\text { - Loitering } \\
\text { - Speed/volume of traffic (including nearby streets) } \\
\text { - Street fights (and disputes) }\end{array}$ \\
\hline & Stable & $\begin{array}{l}\text { - Deteriorated buildings } \\
\text { - Deteriorated recreation places } \\
\text { - Deteriorated residential units } \\
\text { - Exhaust fumes } \\
\text { - Graffiti (with or without political message } \\
\text { or protest) and graffiti painted over } \\
\text { - Vacant/abandoned buildings (homes and others) } \\
\text { - Vacant/abandoned or undeveloped land } \\
\text { - Vandalism } \\
\text { - Vandalized or run-down buildings }\end{array}$ & $\begin{array}{l}\text { - Bar-windowed buildings } \\
\text { - Crime (assaults, robbery, muggings...) } \\
\text { - Minority concentration } \\
\text { - Mother-only households } \\
\text { - Poverty (household and individual) } \\
\text { - Prostitution } \\
\text { - Single-parent households }\end{array}$ \\
\hline
\end{tabular}

Note: Designation as temporary or stable is provisionally assigned but empirically testable and should be reevaluated in future work

aesthetics, physical decay, and neighborhood cohesion), we noted that different data collection methods were varyingly suited to certain groups of street-level items. For example, relatively stable items and those capturing aspects of the physical environment are amenable to data collection using virtual audits, whereas social disorder and related social environment characteristics are more amenable to data collection using self-report or ecometric (a combination of socio-economic and environmental) measures. Across data collection approaches, we note the potential to characterize a spectrum from items signaling order/care to those signaling disorder/deterioration.

\section{Implications}

The broad range of terminology obtained from this brief review is important to understand given the rapid growth of interest in measuring and describing neighborhood characteristics. A majority of neighborhood disorder/order measurements were assessed using primary data collection, often relying on resident self-report or investigatory observations conducted in person or using stored images for virtual audits. Items were balanced across signs of order or disorder, and further classification was proposed based on whether items were physically observable and relatively stable over time. 
Research focused more on items posited to be stable rather than temporary. Empirical observation can be used to refine our classification of which items are observed to exhibit stability across months, years, and even decades.

Neighborhood disorder, often broken down into two distinct constructs (physical disorder and social disorder) [18, 36 , is closely related to other terms (some of which have been identified in this review) that have emerged in recent literature, including neighborhood aesthetics, physical decay, and social cohesion $[4,10,12,25 \bullet \cdot]$. Therefore, distinctions and relationships between these concepts can be ambiguous, making related research challenging to assemble and interpret. A more standard application of terminology is needed to reduce the ambiguity often associated with the use of these concepts in research.

Even though our snowball sampling was initiated with the terms physical and neighborhood disorder, we did not include only studies using these specific two terms. The methodology employed entailed actively searching for and reviewing papers that used synonymous or related terms to describe neighborhood environments. We are, however, aware that this strategy made it more likely than not to capture articles that employed these two specific terms, so the proportions of studies under each term in Table 2 should not be taken as representative of the broader literature.

Planned neighborhood observations may benefit from considering whether aspects such as the temporal permanence (temporary/stable) and the physical observability (physical/social) of the specific items is well matched to the measurement strategy, and considering strategies to improve the accuracy and precision of these measurements. As physical disorder/order assessment is extended to new settings, individual items may need to be assessed for differential item functioning and for alignment with what residents understand as representing physical disorder/order. For example, vegetation may be an indicator of disorder in rural settings but an indicator of order in urban settings. Also, graffiti could in some instances be part of urban renovation in informal settlements and may be considered as art potentially indicating order. Hence, certain items may need to be adapted prior to measurement depending on the setting. In addition, many items relevant to physical disorder/order incorporate subjective evaluation such as distinguishing between graffiti and a mural based on aesthetic value and inferred purpose, further rendering the systematization of protocols more challenging.

\section{Strengths and Limitations}

The current rapid review provides an orientation to the data collection methods, terms, and items commonly used in health-relevant research on neighborhood disorder/order. However, our focus on title searching followed by a snowball approach to expanding the pool of included articles was not comprehensive, and there may be additional available terminology and measurable items that warrant consideration for future work describing neighborhoods. Although the included articles suggest a wide range of terms and items have been used, this review may have omitted literature with relevance to the subject matter and thus underestimated the heterogeneity of terms and items used.

\section{Conclusions}

Understanding the influence of neighborhood disorder/ order on population health is challenging due to the diversity of terms and items used. Clear definitions and consolidation of terminology in the neighborhood disorder/order literature would facilitate comparisons and synthesis across related studies. Efforts toward standardization of research and terminology on the neighborhood disorder/order concept may benefit from consolidating measurement items within our proposed strata, as well as refinement of how items are classified and empirical investigation of how items are most reliably measured. Where specific settings require the inclusion of more novel or tailored items, these could be used alongside a common set of items to ease comparisons across settings and clarify the added value of settingspecific additions.

Acknowledgments The authors thank Jody Bayer, Rich Remegio, Vaishnavi Vaidya, and the entire Informal Communities Project team at the Urban Health Collaborative, Drexel University for their suggestions, feedback, and support throughout this piece.

Funding Information Dana and David Dornsife provided the Drexel University Dornsife School of Public Health the funding support to make this study possible. Gina Lovasi's contributions to this work were supported by the Salud Urbana en América Latina (SALURBAL)/Urban Health in Latin America project which is funded by the Wellcome Trust [205177/Z/16/Z]. More information about the project can be found at www.lacurbanhealth.org.

\section{Compliance with Ethical Standards}

Conflict of Interest The authors declare that they have no conflict of interest.

Human and Animal Rights All reported studies/experiments with human or animal subjects performed by the authors have been previously published and complied with all applicable ethical standards including the Helsinki declaration and its amendments, institutional/national research committee standards, and international/national/institutional guidelines. 
Open Access This article is distributed under the terms of the Creative Commons Attribution 4.0 International License (http:// creativecommons.org/licenses/by/4.0/), which permits unrestricted use, distribution, and reproduction in any medium, provided you give appropriate credit to the original author(s) and the source, provide a link to the Creative Commons license, and indicate if changes were made.

\section{References}

Papers of particular interest, published recently, have been highlighted as:

- Of importance

•- Of major importance

1. Kawachi I. Subramanian S. Neighbourhood influences on health: BMJ Publishing Group Ltd; 2007.

2. Bowling A, Barber J, Morris R, Ebrahim S. Do perceptions of neighbourhood environment influence health? Baseline findings from a British survey of aging. J Epidemiol Community Health. 2006;60(6):476-83.

3. Latkin CA, Curry AD, Hua W, Davey MA. Direct and indirect associations of neighborhood disorder with drug use and high-risk sexual partners. Am J Prev Med. 2007;32(6):S234-S41.

4. Litt JS, Soobader M-J, Turbin MS, Hale JW, Buchenau M, Marshall JA. The influence of social involvement, neighborhood aesthetics, and community garden participation on fruit and vegetable consumption. Am J Public Health. 2011;101(8):1466-73.

5. Mason MJ, Light JM, Mennis J, Rusby JC, Westling E, Crewe S, et al. Neighborhood disorder, peer network health, and substance use among young urban adolescents. Drug Alcohol Depend. 2017;178:208-14.

6. NRC. Exposure Science in the 21st Century: a Vision and a Strategy: National Academies Press; 2012.

7. Calvert WJ. Neighborhood disorder, individual protective factors, and the risk of adolescent delinquency. ABNF J. 2002;13(6):127.

8. Cerdá M, Tracy M, Messner SF, Vlahov D, Tardiff K, Galea S. Misdemeanor policing, physical disorder, and gun-related homicide: a spatial analytic test of" broken-windows" theory. Epidemiology. 2009:533-41.

9. Douglas JA, Briones MD, Bauer EZ, Trujillo M, Lopez M, Subica AM. Social and environmental determinants of physical activity in urban parks: Testing a neighborhood disorder model. Prev Med. 2018;109:119-24. This paper is important as it is one of the first recent papers to point out that physical disorder may lead to decreased physical activity in urban environments (urban parks).

10. Henderson H, Child S, Moore S, Moore JB, Kaczynski AT. The influence of neighborhood aesthetics, safety, and social cohesion on perceived stress in disadvantaged communities. Am J Community Psychol. 2016;58(1-2):80-8.

11. Kelly CM, Schootman M, Baker EA, Barnidge EK, Lemes A. The association of sidewalk walkability and physical disorder with arealevel race and poverty. J Epidemiol Community Health. 2007;61(11):978-83.

12. Marco M, Gracia E, Martín-Fernández M, López-Quílez A. Validation of a Google Street View-based neighborhood disorder observational scale. J Urban Health. 2017;94(2):190-8.

13.• Diez Roux AV, Slesinski SC, Alazraqui M, Caiaffa WT, Frenz P, Jordán Fuchs R, et al. A Novel International Partnership for Actionable Evidence on Urban Health in Latin America: LACUrban Health and SALURBAL. Global Chall 2018;1800013.
This paper calls for international collaborations and partnerships in studying and describing neighborhood environments. This is very relevant to the context of our review as our review itself is aimed at promoting such partnerships in order to achieve internationally accepted standards for neighborhood order/disorder measurements.

14. Reid CE, Kubzansky LD, Li J, Shmool JL, Clougherty JE. It's not easy assessing greenness: A comparison of NDVI datasets and neighborhood types and their associations with self-rated health in New York City. Health Place. 2018;54:92-101. This paper is important as it uses a very large data set with varying neighborhood types to assess the relationship between health and neighborhood order/disorder.

15. Poulsen MN, Knapp EA, Hirsch AG, Bailey-Davis L, Pollak J, Schwartz BS. Comparing objective measures of the built environment in their associations with youth physical activity and sedentary behavior across heterogeneous geographies. Health Place. 2018:49:30-8. This paper is important because it is one of the only recent papers that specifically emphasizes on measurable aspects of neighborhood environments in assessing neighborhood order/disorder. The authors propose simple objective measures to measure neighborhood disorder/order.

16.• Quistberg DA, Roux AVD, Bilal U, Moore K, Ortigoza A, Rodriguez DA, et al. Building a Data Platform for Cross-Country Urban Health Studies: the SALURBAL Study. J Urban Health. 2018:1-27. This paper is very important because it proposes a data platform for understanding neighborhood disorders across different countries and settings, hence encouraging collaboration among researchers in coming up with practical ways of studying and understanding various neighborhood environments.

17. Cunradi CB. Intimate partner violence among Hispanic men and women: The role of drinking, neighborhood disorder, and acculturation-related factors. Violence Vict. 2009;24(1):83.

18. LaGrange RL, Ferraro KF, Supancic M. Perceived risk and fear of crime: Role of social and physical incivilities. J Res Crime Delinq. 1992;29(3):311-34.

19. Erving G. Behavior in public places: notes on the social organization of gatherings. N Y. 1963.

20. Hunter A. Private, parochial and public social orders: The problem of crime and incivility. The challenge of social control: Citizenship and institution building in modern society. 1985.

21. Sampson RJ, Raudenbush SW. Systematic social observation of public spaces: A new look at disorder in urban neighborhoods. Am J Sociol. 1999;105(3):603-51.

22. Ross CE, Jang SJ. Neighborhood disorder, fear, and mistrust: The buffering role of social ties with neighbors. Am J Community Psychol. 2000;28(4):401-20.

23. Skogan WG. Disorder and decline: Crime and the spiral of decay in American cities. 1990.

24. Goodman LA. Snowball sampling. Ann Math Stat. 1961:148-70.

25.• Robinette JW, Charles ST, Gruenewald TL. Neighborhood cohesion, neighborhood disorder, and cardiometabolic risk. Soc Sci Med. 2018;198:70-6. This paper is very important as they report measures for some social aspects indicative of the state of order/disorder of neighborhood environments. They introduce concepts such as neighborhood cohesion and neighborhood aesthetics; aspects which are very crucial to our current understanding of perceived neighborhood disorders by both neighborhood residents and external observers.

26. Wei E, Hipwell A, Pardini D, Beyers JM, Loeber R. Block observations of neighbourhood physical disorder are associated with neighbourhood crime, firearm injuries and deaths, and teen births. J Epidemiol Community Health. 2005;59(10):904-8.

27. Costa DAS, Mingoti SA, ACdS A, Xavier CC, Proietti FA, Caiaffa WT. Indicadores dos atributos físicos e sociais da vizinhança 
obtidos pelo método de Observação Social Sistemática. Cad Saude Publica. 2017;33:e00026316.

28. Mooney SJ, Bader MD, Lovasi GS, Neckerman KM, Teitler JO, Rundle AG. Validity of an ecometric neighborhood physical disorder measure constructed by virtual street audit. Am J Epidemiol. 2014;180(6):626-35.

29. Oropesa RS. Neighbourhood disorder and social cohesiveness among immigrants in a new destination: Dominicans in Reading, PA. Urban Stud. 2012;49(1):115-32.

30. de Almeida CF, de Lima Friche AA, Jennings MZ, de Souza Andrade AC, Xavier CC, Proietti F, et al. Contextual characteristics associated with the perceived neighbourhood scale in a crosssectional study in a large urban centre in Brazil. BMJ Open. 2018;8(8):e021445.

31. Andrade ACS, Peixoto SV, AAdL F, Goston JL, César CC, Xavier $\mathrm{CC}$, et al. Social context of neighborhood and socioeconomic status on leisure-time physical activity in a Brazilian urban center: The BH Health Study. Cad Saude Publica. 2015;31:136-47.

32. Zandieh R, Martinez J, Flacke J, Jones P, Van Maarseveen M. Older adults' outdoor walking: Inequalities in neighbourhood safety, pedestrian infrastructure and aesthetics. Int J Environ Res Public Health. 2016;13(12):1179.

33. Ross CE, Mirowsky J. Neighborhood disadvantage, disorder, and health. J Health Soc Behav. 2001:258-76.

34. Miles R. Neighborhood disorder, perceived safety, and readiness to encourage use of local playgrounds. Am J Prev Med. 2008;34(4): 275-81.

35. Latkin CA, Tseng T-Y, Davey-Rothwell M, Kennedy RD, Moran MB, Czaplicki L, et al. The Relationship between Neighborhood Disorder, Social Networks, and Indoor Cigarette Smoking among Impoverished Inner-City Residents. J Urban Health. 2017;94(4): 534-41.

36. Baran PK, Smith WR, Moore RC, Floyd MF, Bocarro JN, Cosco NG, et al. Park use among youth and adults: examination of individual, social, and urban form factors. Environ Behav. 2014;46(6): 768-800.

Publisher's Note Springer Nature remains neutral with regard to jurisdictional claims in published maps and institutional affiliations. 